\title{
Objective: Winning or Learning? A Study of Marketing Simulation
}

\section{Games}

\author{
Myriam Ertz ${ }^{1}$ \\ ${ }^{1}$ School of Management Sciences, University of Quebec in Montreal, Montreal, Canada \\ Correspondence: Myriam Ertz, School of Management Sciences, University of Quebec in Montreal, Montreal, \\ QC., H2X 3X2, Canada. Tel: 1-514-987-3636. E-mail: myriam.ertz@gmail.com
}

Received: January 21, 2016

Accepted: February 18, 2016 Online Published: March 25, 2016

doi:10.5539/ijms.v8n2p13

URL: http://dx.doi.org/10.5539/ijms.v8n2p13

\begin{abstract}
Simulation Games are now broadly used by scores of business schools, especially in marketing. These games favour active, feedback-based learning, normally in groups, and exhibit characteristics of intrinsic motivation channelled into a learning perspective. If Simulation Games clearly spur individuals to "win", it is more difficult to assess whether they effectively empower them to "learn". This study is a literature review that examines the limitations of learning effectiveness of Simulation Games. The article then proposes two theses intended to explain the potential causes of Simulation Game ineffectiveness: (1) the incompatibility of evaluation tools and (2) pedagogical deficiency inherent in Simulation Games.
\end{abstract}

Keywords: simulation games, experiential learning, learning effectiveness, learning outcomes, cognitive insight

\section{Introduction}

Recourse to "serious" (Sauvé \& Kaufman, 2010) or "instructional" games has increased considerably in the last decade (Garber et al., 2012). Indeed, some $50 \%$ of business schools in developed countries use them (Faria et al., 2008). These games may be grouped into several categories, namely games, simulations or a combination of the two known as simulation games (SGs). Artificial by nature, the games place players in competitive or conflictual situations in which they must formulate winning strategies based on a pre-established set of rules (Sauvé \& Kaufman, 2010). A typical example would be a chess game. In contrast to games, simulations represent depictions of reality, albeit simplified and reduced to a set of parameters with interaction between the different variables deemed to be dynamic (Garris, Ahlers, \& Driskell, 2002). Flight simulators used in airline pilot training are manifest examples of simulation-based learning. Then there are Simulation Games (SG) which exhibit the characteristics of both simulations and games. These games incorporate players, generally divided into two or more competing teams, who develop strategies with the ultimate goal of winning either by maximizing market share, profits or simulation game objectives (Sauvé \& Kaufman, 2010). In SG, losses remain confined within the limits of the game and do not extend beyond (Garris, Ahlers, \& Driskell, 2002).

SG have become more sophisticated and more complex over the past forty years, while simultaneously transforming into more user-friendly tools (Faria et al., 2008). As a result, they spur learners to be more enthusiastic, focused, engaged and self-motivated (Garris, Ahlers, \& Driskell, 2002, p. 444). However, technological advances associated with SG may not necessarily have spawned pedagogical progress (Faria et al., 2008). Indeed, the broader issue of pedagogical efficiency must be resolved if marketing educators are to be able to modulate them more effectively (Vos, 2014). Few studies have examined the learning effectiveness of SG and those which have point to contradictory pedagogical outcomes (Garber et al., 2012). Learning effectiveness refers, on the one hand, to the achievement of stated learning goals (Chou \& Liu, 2005) of the course or the simulation game, and as the improvement of performance in the workplace (Vos \& Brennan, 2012), on the other hand.

The intrinsic dimensions of games are often fraught with elements of risk such as sensory stimuli, mystery, challenge, fantasy or gain that divert learners from their primary objective which is to learn (Garris, Ahlers, \& Driskell, 2002). SG therefore has a tendency to become lacklustre in pedagogical terms. "Learning [...] becomes important in the same way that it would if highway toll takers made everyone perform an arithmetic problem or recite a line of Shakespeare before being permitted to continue driving" (Brody, 1993, p. 55, in Garris, Ahlers, \& Driskell, 2002). 
Despite the absence of a body of corresponding indicia, recurring clues tend to evidence the learning effectiveness of SG. However, consistent research remains insufficient to conclude that simulations are indeed effective (Garber et al., 2012). This study answers therefore the following research questions: (1) what are the theoretical foundations of SG? (2) To what extent is SG pedagogically effective? (3) What are the potential causes underlying SG learning ineffectiveness? Hence this article reviews relevant literature that, first, seeks to determine the theoretical foundations justifying recourse to SG, and then point up the challenges associated with $\mathrm{SG}$ in terms of learning effectiveness before providing explanations related to the reasons for a potential ineffectiveness of SG. Suggestions will subsequently follow to enable marketing educators to make better use of SG for successful, active learning.

\section{Theoretical Foundations}

\subsection{Ontological and Epistemological Anchoring}

Active learning. SG represents a form of active, student-centric learning whereby students learn by doing (Garris, Ahlers \& Driskell, 2002). According to Wellington et al. (2011), learning is moving away from a teacher-centric or lecture environment to a more participatory environment in which technology plays an important role. Learners are increasingly able to ground their learning and understanding based on their own personal experience. Contextualized learning (Garber et al., 2012) of this nature is in keeping with trends in the teacher-centric learning paradigm (pedagogy of supply) towards more student-centric instruction (pedagogy of demand) and, ultimately, the development of competence (pedagogy of competence). The underlying objective is to develop deep learning by invoking high level cognitive competencies (analyse, evaluate, create) as opposed to surface learning which involves lower level competencies (memorize, understand and apply) or strategic learning which entails learners adapting to instructor requirements (Ramsden, 2003).

Analogical reasoning. SG draw upon a fundamental principle in human cognition called "analogical reasoning". Gentner (2003) defines it as a "kind of reasoning that applies between specific exemplars or cases, in which what is known about one exemplar is used to infer new information about another exemplar (...) when there are substantial parallels across different situations, there are likely to be further parallels" (p. 106). When confronted with a new situation, learners try to notice similarities and analogies with situations to which they have been exposed to in the past (Gick \& Holyoak, 1980, 1983). They then re-activate and re-implement cognitive tasks and processes used in the past situation in order to tackle the new situation (Vosniadou \& Ortony, 1989; Sternberg, 1977). SG are a kind of analogical problem solving activity since learners confront and compare the similarities between understood and new knowledge about marketing, that is between their experience and prior knowledge of business principles to that derived from the SG (Loewenstein, Moore, \& Weber, 2003). Besides, because the SG shares similarities with real-world businesses (i.e., it is an analogy or a metaphor of it), the transfer of knowledge operates more easily.

Mastery. As the popular saying states "Practice makes perfect". Classic works on chess mastery found that time-on-task repetition is key to learning (e.g., Chase \& Simon, 1973; Simon \& Chase, 1973; Ross, 2006). A player may require a thousand games to gain some mastery at chess. As Colby et al. (2011) suggest, business disciplines are no different to engineering, medicine and law in that they are professional disciplines which require practice in order to reach mastery. Engineering students multiply works simulations and experimentations, medicine students practice their skills on corpses, and law students exercise their defense speeches through plea and moot court competitions, in addition to their compulsory internships within firms, hospitals and legal offices, respectively. Business students do not seem to get such a great amount of hands-on practice during their business curricula except perhaps for the lucky ones who might get an internship or other types of field experience. But with so little exposition to real-world practice how can it be expected from learners to master business practice? SG is a means to incorporate more practical business training during learners' curriculum.

Constructivist learning paradigm. SG fall within the confines of constructivist learning (Ménard \& St-Pierre, 2014) since they strive to steer learner activities while allowing learners to exercise control over their own individual learning process (Wellington et al., 2011). Given that SG have been organized in groups since the outset and that these exercises have become increasingly more commonplace (Faria et al., 2008), SG are also framed into a socio-constructivist paradigm such as that conceptualized by Vygotski in 1934 (Ménard \& St-Pierre, 2014). It might therefore prove of interest to compare the pedagogical value of SG with that of other group-based learning activities.

\subsection{Comparative Advantages}

SG presents some advantages over other learning methods. According to Kolb \& Kolb (2009), SG is grounded in 
the Experiential Learning Theory (Kolb, 1984) which helps learners to "learn how to learn" (p. 297). Experiential learning incorporates the following components (Svinicki \& McKeachie, 2014, p. 204-205): “(1) The learning uses real-world situations, problems, equipment, or actions to the extent possible; (2) The situations involve complex, ill-defined problems that don't have a simple answer and may even have more than one possible answer; (3) The situations involve the learners in solving a problem that reflects the kinds of problems they would encounter in the real world using the real tools of the discipline; (4) The instructor is a resource, but not the leader of the problem-solving task; (5) When the learners have come to a solution, they spend an equal amount of time reflecting on how they reached their solution and getting feedback about the quality of their proposed solution. In addition to Experiential learning methods comprise the case method, problem-based learning, field experience, games / role playing / simulations.

Case studies perhaps represent the most widespread pedagogical activity in management. Case studies enable one to adopt different perspectives-a concept which Colby et al. (2011) term multiple framing-and to "work on complexity as a means to education" (Roegiers, 2012, p. 49) for subsequent reuse in internships, postgraduate theses and portfolios. However, although case studies require analysis and in-depth study given that learners must assume the perspective or worldview of others in different and often complex situations, the pedagogical value of this activity is limited because it does not provide feedback. Students identify an issue and proffer recommendations but are not graded on the effective implementation of the latter (Faria et al., 2008). The experiential dimension is therefore limited. Besides, case studies suffer from contextual issues since solutions to problems faced by a company in a given context may not work for another company in another context. Generalizability is at stake and evidence-based principles of education are de-emphasized (Mesny, 2013; Rousseau \& McCarthy, 2007). There is "an inherent disconnect between case-based teaching and an evidence-based approach to management education" (Gamble \& Jelley, 2014, p. 434). The same holds true for role playing and problem-based learning, especially if the learning activities fail to include an implementation phase followed by feedback.

SG on the other hand draw upon quantities of evidence and principles derived from business research and practice to provide for effective decision-making in a secure, real-world-like environment, problem-solving, receipt of immediate feedback, reflection on the positive and/or negative consequences of decisions taken, generalization of new principles, and adjustment to comments and feedback in a continuing, iterative, trial-and-error process (Garber et al., 2012). This process is closely associated with the four stages of Kolb's (1984) learning spiral whereby the learner: (1) experiences concrete decision-making; (2) engages in reflection and observations upon receipt of feedback relating to the decision-making process; (3) conceptualizes, at an abstract level, new norms, rules and principles based on the aforesaid reflection ; and, (4) experiments actively once again in a reactive process to substantiate the relevance of newly acquired concepts (Garber et al., 2012).

Learners are therefore encouraged to develop meta-cognition or learning about their learning process which has been proven to lead to superior learning performances (Kamp et al., 2014; Kuyper, Van der Werf \& Lubbers, 2000; Schunk, 2008). Contrarily to other experiential methods, SG provides feedback and enables to take strategic decisions in short periods of time. Consequently, "by consciously following a recursive cycle of experiencing, reflecting, thinking, and acting, [learners] can increase their learning power" (Kolb \& Kolb, 2009, p. 297). Learners' identities are encouraged to migrate from fixed self (deterministic, static learning process) to learning self (indeterministic, dynamic learning process), which is conducive to metacognition (reflection on the learning process) (Schunk, 1995). Hence, "when a concrete experience is enriched by reflection, given meaning by thinking, and transformed by action, the new experience created becomes richer, broader and deeper" (Kolb \& Kolb, 2009, p. 309). This process ultimately leads to a form of deep learning in which "new facts and ideas are critically examined before being tied to existing cognitive structures and numerous links are made between ideas" (Ramsden, 2003). This process may therefore be depicted as a learning spiral which increases in diameter with each successive round of games.

Client-based or client-financed projects have also become increasingly popular in business schools. Students are required to undertake a real project that is sponsored by a company or organization and present their findings and suggestions at the end of the semester. These projects have the advantage of making students active learners and improving the soft skills students need to succeed in the business community (Clark, King, \& Jurn, 2012). Such skills include problem solving, analytical-, creative-, and critical-thinking skills, decision making, teambuilding and communication abilities (Clark, Jurn, \& King, 2013). Similarly to case studies and problem-based learning, client-based projects do not enable students to get feedback before the end of the project. Retroaction comes only at the final presentation to the client. Besides, most projects involve mainly secondary and possibly primary research (Malhotra, 2010), summarized and presented in the form of suggestions and recommendations which 
the organisation is free to implement or not. Therefore, strategic and tactic aspects of decision-making and implementation are not well developed through client-based approaches, contrarily to SG. Although not a panacea, SG exhibits many advantages over other experiential, active learning methods. The next section examines the extent to which these advantages actually translate into learning effectiveness.

\section{Learning Effectiveness}

\subsection{Achievement of Stated Learning Goals}

The first facet of learning effectiveness refers to the achievement of stated learning goals or objectives which, in a computerized activity such as computerized SG, may be captured by learners' final scores, satisfaction levels, self-confidence or reported learning climate (Chou \& Liu, 2005, p. 67-68). More generally, this aspect of learning effectiveness determines whether the activity in question effectively enables learners to learn and can be verified by means of learning outcomes (Mayer, 2011). According to Bloom's taxonomy (Bloom, 1956), these learning outcomes can be divided into three categories: (1) psychomotor; (2) affective; and, (3) cognitive. "Each domain is presented as a hierarchy of learning such that learning at higher levels is dependent on having attained knowledge and skills at lower levels" (Vos, 2014, p. 77). SG impacts the achievement of outcomes in a number of different ways. Psychomotor results relate more to another facet of learning effectiveness, namely the improvement of performance in the workplace. This aspect is explained at greater length in the following section.

Affective learning outcomes refer to the positive thoughts and feelings about SG exhibited by learners (Young, Klemz, \& Murphy, 2003), as SG make it possible to impact attitudes. Positive or negative reinforcement indeed influences levels of learner confidence, self-esteem, self-efficacy, as well as general attitudes dispositions (Garris, Ahlers, \& Driskell, 2002). Garber et al. (2012) demonstrated that SG is evaluated positively by all learner styles based on the typology developed by Kolb in 1984 (divergers, assimilators, convergers and accommodators). As SG extends to all phases of the learning cycle, learners can define for themselves the actual nature of the game. Furthermore, since SG draw on the characteristics of games, they boost learner motivation, involvement and time commitment compared with other forms of pedagogical activities (Garris, Ahlers, \& Driskell, 2002; Young, Klemz, \& Murphy, 2003; Faria, 2001).

Cognitive learning outcomes tend to generate the most mixed results. Generally speaking, SG help develop key marketing notions and concepts (Garber et al., 2012), as well as quantitative skills transposable to finance and accounting (Wellington et al., 2011), with integration of these skills fostering a multidisciplinary transfer of knowledge. However, learning may only be valid at lower levels, activating mainly basic competencies in Bloom's typology (remember, understand and apply) (Anderson \& Lawton, 2009; Hsu, 1989; Brennan \& Vos, 2013). A marketing training session "requires students to apply concepts and theories learned from other contexts; analyse results; measure performance, market and competitor data to improve decision-making; synthesise a number of ideas and concepts (create marketing plans, integrate marketing mix elements); and, evaluate their overall performance [based on] a range of indicators" (Vos, 2014, p. 78). These high level competencies (analyse, synthesize and evaluate) may not be well developed by means of SG (Anderson \& Lawton, 2009).

\subsection{Performance Improvement in the Workplace}

It is difficult to find evidence that marketing education in general helps in marketing careers (Hunt, Chonko, \& Wood, 1986), although some support has been found for the effectiveness of advertising education (Hunt, Chonko, \& Wood, 1987). Recently, some support has emerged for the benefits of sales education in college (Bolander, Bonney, \& Satornino, 2014). However, college GPA has a low correlation with career success (Roth \& Clarke, 1998), suggesting that much of what is learned in post-secondary education has only a small impact on career success. These studies do not focus on the SG method in particular, but consider business education in general. Based on the findings in the literature, conceptual simulation games in advertising and sales might a priori have an effect on career success but the identification of career benefits of participating in a SG at the disciplinary remains difficult.

SG leads to the development of motor and behavioural abilities, or psychomotor learning outcomes which refer to behavioural learning skills (Garris, Ahlers, \& Driskell, 2002). Performance improvement in the workplace determines "whether students have learning gains from participating in simulations [...], linking participation in SG during a course of study with career mobility and salary level" (Vos, 2014, p. 80). While the achievement of stated learning goals of SG has been established in part, performance improvement in the workplace can only be inferred. There may indeed be some causality between participation in SG and future career success. Vos (2014), for example, cites several studies which make a case for faster career development and higher salaries (Wolfe \& Roberts, 1993; Cronan \& Douglas, 2012). There seems to be a link between SG and on-the-job skills in matters 
of communication, teamwork, decision-making, adaptability, and organizational abilities (Teach \& Govahi, 1988), as well as integrated understanding of business processes, mastery of enterprise systems management, and enterprise resource planning (ERP) (e.g., SAP) (Cronan \& Douglas, 2012; Faria \& Wellington, 2005). Given the diversity of reported impacts generated by SG and the characteristics of the latter, results such as teamwork and decision-making are reasonably well supported, whereas other outcomes are so specific (SAP skills) or far-fetched (faster career advancement, higher salaries) that they could owe to inferred causality. Other variables indeed enter more significantly into play and provide for the attainment of these results (e.g., SAP certification, choice of industry or job position), possibly indicating that these studies are fraught with spurious correlations.

In short, performance improvement in the workplace cannot be established without taking into account a multitude of other variables in a regressive whole. Young, Klemz, \& Murphy (2003) undertook work of this nature but only to predict aspects of learning performance, impact and class grades. SG has no significant effect on the regression equation as a whole but does appear to enhance greatly time commitment and motivation to study.

Overall, SG enables one to develop behavioural competencies such as relational capabilities and decision-making skills transferable to the professional realm and indicative of a certain measure of performance improvement in the workplace (Vos \& Brennan, 2012). Although these "softer" competencies are the object of ever increasing research by employers, they remain little present in the classic curricula of modern-day business schools (Navarro, 2008). Finch, Nadeau, \& O'Reilly (2012) conducted an importance-performance analysis and found that the top current priority of practitioners in marketing is knowledge related to areas associated with measuring return-on-investment and strategic marketing. Their findings also emphasize the importance of meta-skills perceived as high priorities for improvement, including the ability to creatively identify, formulate, and solve problems; the ability to write in a business environment; and the ability to set priorities, whereas design-related skills, production and merchandising are of lesser importance. Problem-solving as well as soft skills seem to be of utmost importance (Finch et al., 2013). Experiential learning such as SG may therefore contribute to some extent to competencies improvement in the workplace since they increase mathematical abilities (i.e., marketing and financial concepts) (Wellington et al., 2011). Also, their increasingly strategic scope tightly integrated with other disciplines fosters the practice of strategic marketing (Faria et al., 2008). Meta-skills are related to students ability to learn how to learn which is a fundamental aspect of SG by means of the meta-cognitive processes that they induce (Kolb \& Kolb, 2009). SG may therefore have a positive impact on performance in the workplace but they need to be constantly aligned to the expectations of employers.

\section{Learning Ineffectiveness of Simulation Games}

\subsection{Incompatibility of Evaluation Tools}

The absence of conclusive evidence of the learning effectiveness of SG can be interpreted in two different ways: (1) incompatibility of tools of measurement; or (2) pedagogical deficiency inherent in SG.

In the case of the first point, learning outcomes may prove inefficient because "in many respects, Bloom's taxonomy has been the anchor for assessing whether learning occurs in business simulations" (Anderson \& Lawton, 2009, p. 196). However, if these learning outcomes cannot be attained, it may be because what is to be measured remains vague and ambiguous (Vos, 2014). Besides, learning outcomes generate methodological benefits without necessarily taking into account one or other of learning complexity and learner involvement, the latter in particular. Learner involvement is indeed notably higher when the instructor uses SG in place of learning modes (Vos, 2014). Motivation, involvement and other affective learning outcomes increase considerably (Faria et al., 2008; Gee, 2003; Garris, Ahlers, \& Driskell, 2002) as does time commitment (Young, Klemz, \& Murphy, 2003). However, these results are typically not well evaluated or captured, probably owing to their inherent subjectivity and the difficulty involved in quantifying them.

Besides, whether for cognitive, affective or behavioural learning outcomes, both researchers and teachers rely heavily on self-reported measures in addition to the final score obtained at the SG. However, self-reports of knowledge gain (learning) is completely independent of actual learning (Sitzmann et al., 2010). The same holds true for self-reports of affective or behavioural gains.

Finally, the focus on quantifiable learning outcomes constitutes confinement to the paradigm of efficacy which depends, among others, on the quantification of learning outcomes (Roegiers, 2012). An approach of the like also impedes any headway towards a paradigm of long term efficacy which would incorporate humanism and more abstract variables such as motivation, human relationships and self-confidence (Roegiers, 2012), thereby necessarily implying integration of little considered affective learning outcomes. 


\subsection{Deficiencies Relating to Simulation Games}

In the case of the second point, SG shares a greater measure of responsibility. For SG to be internally valid, participants must seize the specific nature of game parameters in order to make good decisions (Whiteley, Leduc, \& Dawson, 2004). The first step, referred to as cognitive insight, supposes that learners understand the response functions of a game's dynamic parameters, which is to say the relationship between input (e.g., price) and output (e.g., sales). This step parallels the preliminary conditions of problem-based learning pedagogy, namely "(1) understanding the concepts and (2) understanding the principles that link concepts" (Gijbels et al., 2005, p. 44). If cognitive insight is achieved, then learners should make decisions which are consistent with the perceived versus the real importance of the game. This step, called cognitive-behavioural consistency (Whiteley, Leduc \& Dawson, 2004), represents the last stage of problem-based learning and involves "(3) aligning concepts and principles to conditions and procedures for application" (Gijbels et al., 2005, p. 44). Decision-making performance should improve as the gap between perceived and real importance diminishes. Whiteley, Leduc and Dawson (2004) demonstrated that learners are generally incapable of determining the nature of the response functions of game parameters. If cognitive insight does not occur, the result is an incapacity to take the proper decisions. A number of other studies also demonstrate that cognitive-behavioural consistency is not established (Whiteley, Leduc, \& Dawson, 2004). In other words, even if the gap between the perceived and real importance of the response functions of game parameters is reduced, learners do not necessarily make decisions consistent with their determination of the structure of the aforesaid response functions.

Cognitive insight may be construed as the formation of an attitude. However, given the ever increasing sophistication of SG, especially in marketing, parameters have become more and more numerous and the relationships between them more and more complex (Faria et al., 2008). Participants having developed an attitude or pre-conceived notion of the general nature of the different parameters of a simulation game will have an advantage over others as they will find themselves in a situation of high cognitive involvement (Whiteley, Leduc, \& Dawson, 2004). Their attitude precedes their behaviour, whereas for learners with low cognitive involvement, no specific attitude precedes behaviour. According to the experiential learning spiral (Kolb \& Kolb, 2009), once the consequences of behaviour (initial rounds of a simulation game) can be established, attitudes form and positively or negatively reinforce initial behaviour. In sum, SG favour learners with a substantial intellectual background as they will be more likely to determine the response functions in a more effective manner. For example, students with higher general point average (GPA) scores and those with an above-average knowledge of the principles of marketing, finance and accounting tend to perform better in marketing SG (Wellington et al., 2011). Prior knowledge indeed constitutes an internal condition conducive to student engagement. This condition, albeit necessary, does not suffice to spawn learning (Sauvé \& Kaufman, 2010). Cognitive involvement would appear to be necessary to achieve cognitive insight and subsequent cognitive-behavioral consistency. That said, involvement is enhanced whenever learners have prior knowledge at their disposal.

Readers will appreciate that a mechanism such as this can almost certainly apply to the quasi-totality of pedagogical activities. SG, however, are somewhat unique. Firstly, since teachers can themselves modulate the parameters, the latter do not fully reflect reality (Whiteley, Leduc, \& Dawson, 2004). One must then ask just how relevant a costly simulation activity is when reduced to a simple game no longer a reflection of reality? Secondly, the fact that few learners achieve a level of cognitive insight owes to the very nature of the simulation game and the potential to engender (1) dispersion and (2) noise. Dispersion refers to learner focus on certain game-based performance criteria (e.g., profits) not included, in whole or in part, in the bases of evaluation for the simulation game activity at hand. Dispersion can also be spawned by competition, by overwhelming fears at the outset of the simulation game activity and by the excessive variety of decisions which need to be taken (Vos, 2014). Noise, as a concept, encompasses all issues arising from the failure of a team to reach a consensus respecting the response functions. Noise can owe to the presence of a large number of teams impacting game results. Indeed, the probability, for one given team, of finding the proper response functions is statistically higher when teams are fewer in number. Noise may also result from interaction by competing teams in relation to the response functions (Whiteley, Leduc, \& Dawson, 2004). Issues of the like may indeed undermine the determination of the response functions (cognitive insight), and exert an adverse influence on the subsequent stage of cognitive-behavioral consistency.

\section{Suggestions and Conclusion}

\subsection{Simulation Games and a Program-Approach}

The mixed results obtained respecting the learning effectiveness of SG are symptomatic of deeper divides 
relating to business school curricula. Prégent, Bernard, \& Kozanitis (2012) (p. 1) define a course approach as the organization of course material within the framework of an individualistic program of study where each professor is responsible for preparing and presenting course material to the best of his or her ability. Commonly referred to as the silo approach, this technique turns out traditional I-shaped graduates (Bajada \& Trayler, 2013). In contrast, in a program approach "courses are based on a "training project" drawn up and followed collectively and longitudinally by the teaching community with the leaders responsible for the teaching of content in a spirit of continuous collaboration and collegiality" (Prégent, Bernard, \& Kozanitis, 2012, p. 1). A transdisciplinary perspective such as this is said to generate T-shaped graduates having a more integrated outlook on business processes (Bajada \& Trayler, 2013).

At the current juncture, the isolated course approach remains the dominant paradigm in management (Prégent, Bernard, \& Kozanitis, 2012). More often than not, SG are initiated by lone enthusiasts who innovate in isolated fashion for their own courses and who rely solely upon their marketing department for the financial support needed to pay simulation game licence fees (Vos, 2014). As a consequence, instructors deploy SG in isolation in one or more specific disciplines (e.g., capstone simulation game) without making allowance for prior student knowledge of discipline-related material. This increases the risk of cognitive insight and cognitive-behavioural consistency being absent from the equation (Whiteley, Leduc, \& Dawson, 2004). Indeed, incompatibility between the knowledge required to engage in SG and the intellectual background of learners leads to a dearth of pre-conceived notions of the different response functions of game parameters. This lack of any preliminary attitude results in low cognitive involvement. In essence, the simulation game amounts to a competition comprising a mix of mystery and luck. A process such as this will only spur the development of lower level cognitive competencies and vague quantitative or numerical technical skills (Wellington et al., 2011) without activating higher level competencies. The outcome is middling at best considering the tremendous investment in time, effort and funding generally allocated to SG (Vos, 2014).

Without representing a panacea, the program approach features a number of advantages. For one, integration into the curriculum means that SG do not rest solely upon the shoulders of a lone instructor isolated and left to his or her own devices. Rather instructors work together with one another around a central training project. The latter is developed upstream and content is "organized in a consistent manner in a sequence of courses that come one after another in a logical pattern" (Prégent et al., 2012). The integration of SG stems from a collective will to guarantee their implementation. Instructors discuss content learned and content being learned (content-in-progress) to ensure that each coincides harmoniously with the requisite response functions of the simulation game, thereby augmenting the occurrence of cognitive insight in learners. As for the response functions, it is paramount that they represent as faithfully as possible the content being taught. Both should eventually mirror verisimilitude with the objective reality to foster practical reasoning.

It might be noted that SG can be used with either course- or program-approach, they are not tied to any one of these approaches. However, the learning effectiveness of SG could be much improved if SG is conducted within the framework of a program-approach. Just as learning occurs through the mediating influence of motivation (Bransford, Brown, \& Cocking, 2000), effective learning may occur through the mediating influence of learning approach. A program approach may provide higher learning effectiveness than a course approach. The differential impact of SG on learning effectiveness through the program approach can be explained by the underlying cognitive insight and subsequent cognitive-behavioural consistency that is enhanced in a program approach in contrast to a course approach.

\subsection{Complementary Suggestions for Improving Cognitive Insight}

Vos (2014) indicated that it is important to know what is to be taught and what is to be evaluated by means of the simulation game. Learning objectives that are clear and concise should be drawn up and communicated to participants prior to the simulation activity. Both the game and related evaluations should provide for the measurement of the stated objectives. Anderson \& Lawton (2009) deemed the competencies developed by means of SG to be of overwhelmingly inferior order, save for the evaluation of affective results. Objectives relating to the development of higher order competencies continue to dominate in the majority of marketing curricula and generate the typical learning outcomes expected in the context of SG (Vos, 2014).

Also noteworthy is the fact that the development of human competencies (empathy, confidence, communications skills) is of ever increasing importance in management (Navarro, 2008). SG, however, contributes little to the development of higher order competencies and do not capture the development of human competencies. This apparent contradiction owes to the fact that students are generally evaluated based on their final simulation game score. Although students may be able to frame marketing in a broader perspective by incorporating financial and 
other interdisciplinary concepts, this may not be reflected in their poor final position in the simulation game. Similarly, although students may develop more enthusiasm, interest, engagement and confidence in marketing by dint of a simulation game, gains are not reflected in their final grades.

How then does one capture higher order, more qualitative learning? Over and above the course approach, one must rethink the formal evaluation of learning results and entertain the use of different forms of evaluation as the simulation progresses, including presentations, essays, peer evaluations (if not already used), mini-quizzes and simulation game logbooks, all in addition to final simulation game scores (Vos, 2014). Most of these latter activities are already commonplace but logbooks and other personal works such as essays or dissertations can be of particular interest in that they may be used conjointly for synthetic and analytic purposes. For example, students can summarize, make overviews, and draft reports or other works using their logbooks (Nadolski et al., 2008; Dumrongrojwatthana \& Trébuil, 2011). They also enable students to understand their thought processes or find the root causes of poor or good performance by retroactively reviewing their writings after having received feedback.

For undergraduates, however, the attainment of the lower three levels of Bloom's taxonomy, especially "application" might just be what is needed, especially when taking into account the employer's perspective (see Finch, Nadeau, \& O'Reilly, 2012; Finch et al., 2013). Getting undergraduates to the highest level in Bloom's taxonomy may not necessarily be very relevant in a professional context and may, in addition, signal a misinterpretation of Bloom's upper three levels which may not be within reach of just any age group contrarily to what Anderson et al. (2001) seem to suggest. It might be recalled that undergraduate education, in opposition to $\mathrm{MS}, \mathrm{MBA}$ and $\mathrm{PhD}$ programs, are not intended at developing the highest levels in Bloom's (1959) original taxonomy and SG would not be an appropriate method to reach these anyways.

More generally, given the low congruence of self-reported knowledge gain and actual learning (Sitzmann et al., 2010), self-reports should be avoided by researchers and teachers. If they need to be used they should at least be complemented by actual measures of learning. Self-reports may best be used as measures of affective learning outcomes.

In order to improve cognitive insight, one could organize warm-up rounds prior to the official start of the simulation game, thereby allowing learner participants to understand the relationships between action and results (Whiteley, Leduc, \& Dawson, 2004). The provision of all the response functions, which might be considered a little too permissive, would have the advantage of flattening knowledge and inspiring students to consider how the various parameters interact with one another, thereby activating higher order competencies. Meetings with, as well as feedback and comments from the instructor would make it possible to detect dysfunctional teams or those exhibiting limited cognitive insight. By assuming a role more akin to that of a coach, the instructor would spur learner motivation and engagement while monitoring gains in cognitive development, the ultimate aim of all manner of SG.

Also, in accordance with the "mastery" principle which stipulates that chess players may require a thousand games to gain some mastery at chess (Chase \& Simon, 1973; Simon \& Chase, 1973; Ross, 2006), students cannot master SG and hence derive the positive benefits associated with SG, if they only play once. Firstly, they should play regularly to get used to the SG and, secondly, frequent playing at SG will also enable them to learn how to derive useful knowledge from SG.

Finally, in order to favour cognitive insight and subsequent cognitive-behavioural consistency, a program approach seems more appropriate than a course approach. But this approach may not provide any improvements in learning if it is not accompanied by complementary actions to ensure appropriate implementation of the SG and adequate measurement of the achievement of stated learning objectives. The combination of both blocks of suggestions tackles therefore issues relating to inherent deficiencies in SG as well as evaluation issues related to the use of inadequate measurement tools.

\section{References}

Anderson, P. H., \& Lawton, L. (2009). Business simulations and cognitive learning: developments, desires and future directions. Simulation \& Gaming, 18(2), 193-216.

Bajada, Ch., \& Trayler, R. (2013). Interdisciplinary business education: Curriculum through collaboration. Education + Training, 55(4/5), 385-402. http://dx.doi.org/10.1108/00400911311326027

Bloom, B. S. (1956). Taxonomy of educational objectives: The classification of educational goals. New York, NY: Longman.

Bolander, W., Bonney, L., \& Satornino, C. (2014). Sales education efficacy examining the relationship between 
sales education and sales success. Journal of Marketing Education, 36(2), 169-181. http://dx.doi.org/10.1177/0273475314536733

Bransford, J. D., Brown, A. L., \& Cocking, R. R. (2000). How people learn: Brand, mind, experience and school. Washington, DC: National Academy Press.

Brennan, R., \& Vos, L. (2014). Effects of participation in a simulation game on marketing students. Numeracy and financial skills. Journal of Marketing Education, 35(3), 259-270. http://dx.doi.org/10.1177/0273475313482928

Chase, W. G., \& Simon, H. A. (1973). Perception in chess. Cognitive Psychology, 4(1), 55-81. http://dx.doi.org/10.1016/0010-0285(73)90004-2

Chou, Sh. W., \& Liu, Ch. H. (2005). Learning effectiveness in a web-based virtual learning environment. Journal of Computer Assisted Learning, 21(1), 65-76. http://dx.doi.org/10.1111/j.1365-2729.2005.00114.x

Clark, G. L., Jurn, I., \& King, M. E. (2013). Client-financed projects: A study of the perceptions of marketing faculty at AACSB accredited schools. Journal of Higher Education Theory and Practice, 13(1), 90-96.

Clark, G. L., King, M. E., \& Jurn, I. (2012). A tutorial guide about how to manage a client-financed project. Journal of Marketing Education, 34(3), 265-283. http://dx.doi.org/10.1177/0273475312457781

Colby, A., Ehrlich, T., Sullivan, W. M., Dolle, J. R., \& Shulman, L. S. (2011). Rethinking undergraduate business education: Liberal learning for the profession. New-York, NY: Jossey-Bassey.

Cronan, T. P., \& Douglas, D. E. (2012). A student ERP simulation game: A longitudinal study. Journal of Computer Information Systems, 53(1), 3-13.

Faria, A. J., \& Wellington, W. J. (2005). Validating business gaming: Business game conformity with PIMS findings. Simulation \& Gaming, 36(2), 259-273. http://dx.doi.org/10.1177/1046878105275454

Faria, A. J., Hutchinson, D., Wellington, W. J., \& Gold, S. (2008). Developments in business gaming: a review of the past 40 years. Simulation Gaming, 40, 464-487. http://dx.doi.org/10.1177/1046878108327585

Finch, D., Hamilton, L. K., Baldwin, R., \& Zehner, M. (2013). An exploratory study of factors affecting undergraduates employability. Education + Training, 55(7), 681-704. http://dx.doi.org/10.1108/ET-07-2012-0077

Finch, D., Nadeau, J., \& O’Reilly, N. (2012). The future of marketing education: A practitioner's perspective. Journal of Marketing Education, 35(1), 54-67. http://dx.doi.org/10.1177/0273475312465091

Gamble, E. N., \& Jelley, R. B. (2014). The case for competition: Learning about evidence-based management through case competition. Academy of Management Learning \& Education, 13(3), 433-445. http://dx.doi.org/10.5465/amle.2013.0187

Garber, L. L., Hyatt, E. M., Boya, Ü. Ö., \& Ausherman, B. (2012). The association between learning and learning style in instructional marketing games. Marketing Education Review, 22(2), 167-183. http://dx.doi.org/10.2753/MER1052-8008220206

Garris, R., Ahlers, R., \& Driskell, J. E. (2002). Games, motivation, and learning: a research and practice model. Simulation \& Gaming, 33, 441-466. http://dx.doi.org/10.1177/1046878102238607

Gentner, D. (2003). Psychology of Analogical Reasoning. Encyclopedia of cognitive science. New York, NY: John Wiley \& Sons.

Gick, M. L., \& Holyoak, K. J. (1980). Analogical problem solving. Cognitive Psychology, 12(3), 306-355. http://dx.doi.org/10.1016/0010-0285(80)90013-4

Gick, M. L., \& Holyoak, K. J. (1983). Schema induction and analogical transfer. Cognitive Psychology, 15(1), 1-38. http://dx.doi.org/10.1016/0010-0285(83)90002-6

Gijbels, D., Dochy, F., Bossche, P. V., \& Segers, M. (2005). Effects of problem-based learning: A meta-analysis from the angle of assessment. Review of Educational Research, 75(1), 27-61. http://dx.doi.org/10.3102/00346543075001027

Hsu, E. (1989). Role-event gaming simulation in management education: A conceptual framework and review. Simulation \& Games, 20(4), 409-438. http://dx.doi.org/10.1177/104687818902000402

Hunt, Sh. D., Chonko, L. B., \& Wood, V. R. (1986). Marketing education and marketing success: Are they related? Journal of Marketing Education, 8(2), 2-13. http://dx.doi.org/10.1177/027347538600800202 
Hunt, Sh. D., Chonko, L. B., \& Wood, V. R. (1987). Advertising education and successful advertising careers: are they related? Journal of Advertising Research, 27(2), 43-52.

Kamp, M. T., Admiraal, W., van Drie, J., \& Rijlaarsdam, G. (2014). Enhancing divergent thinking in visual arts education: Effects of explicit instruction of meta-cognition. British Journal of Education Psychology, 85(1), 47-58. http://dx.doi.org/10.1111/bjep.12061

Kolb, A. Y., \& Kolb, D. A. (2009). The learning way: meta-cognitive aspects of experiential learning. Simulation Gaming, 40, 297-327. http://dx.doi.org/10.1177/1046878108325713

Kolb, D. (1984). Experiential learning: Experience as a source of learning and development. Upper Saddle River, NJ: Prentice Hall.

Kuyper, H., van der Werf, M. P. C., \& Lubbers, M. J. (2014). Motivation, meta-cognition and self-regulation as predictors of long term educational attainment. Educational Research and Evaluation, 6(3), 181-205. http://dx.doi.org/10.1076/1380-3611(200009)6:3;1-A;FT181

Malhotra, N. K. (2010). Marketing research: An applied orientation. Englewood Cliffs, NJ: Prentice-Hall. http://dx.doi.org/10.1108/S1548-6435(2010)6

Mayer, R. E. (2011). Does styles research have useful implications for educational practice? Learning and Individual Differences, 21(3), 319-320. http://dx.doi.org/10.1016/j.lindif.2010.11.016

Ménard, L., \& St-Pierre, L. (2014). Se former à la pédagogie de l'enseignement supérieur [Getting trained for pedagogy in higher education]. AQPC, Canada.

Mesny, A. (2013). Taking stock of the century-long utilization of the case method in management education. Canadian Journal of Administrative Sciences/Revue Canadienne des Sciences de l'Administration, 30(1), 56-66. http://dx.doi.org/10.1002/cjas.1239

Navarro, P. (2008). The MBA core curricula of top-ranked US business schools: A study in failure? Academy of Management Learning \& Education, 7(1), 108-123. http://dx.doi.org/10.5465/AMLE.2008.31413868

Prégent, R., Bernard, H., \& Kozanitis, A. (2012). Enseigner à l'université dans une approche -programme: guide à l'intention des nouveaux professeurs et chargés de cours [Teaching at university using a program approach: Guide intended for new professors and lecturers]. Presses Internationales Polytechnique, Montreal.

Ramsden, P. (2003). Learning to teach in higher education. British Journal of Educational Studies, 30(100), $67-82$.

Roegiers, X. (2012). Quelles réformes pédagogiques pour l'enseignement supérieur? [Which pedagogical reforms for higher education?] Paris: De Boeck.

Ross, P. E. (2006). The expert mind. Scientific American, 295(2), 64-71. http://dx.doi.org/10.1038/scientificamerican0806-64

Roth, P. L., \& Clarke, R. L. (1998). Meta-analyzing the relation between grades and salary. Journal of Vocational Behavior, 53(3), 386-400. http://dx.doi.org/10.1006/jvbe.1997.1621

Rousseau, D. M., \& McCarthy, Sh. (2007). Educating managers from an evidence-based perspective. Academy of Management Learning \& Education, 6(1), 84-101. http://dx.doi.org/10.5465/AMLE.2007.24401705

Sauvé, L., \& Kaufman, D. (2010). Jeux et simulations éducatifs [Instructional games and simulations]. Presses Universitaires du Québec.

Schunk, D. H. (1995). Self-efficacy and education and instruction. In J. E. Maddux (Ed.), Self-efficacy, adaptation, and adjustment: Theory, research, and application (pp. 281-303). New York, NY: Plenum.

Schunk, D. H. (2008). Metacognition, self-regulation, and self-regulated learning: Research recommendations. Educational Psychology Review, 20(4), 463-467. http://dx.doi.org/10.1007/s10648-008-9086-3

Simon, W. G., \& Simon, H. A. (1973). Skill in chess. American Scientist, 61, 393-403.

Sternberg, R. J. (1977). Component processes in analogical reasoning. Psychological Review, 84(4), 353-378. http://dx.doi.org/10.1037/0033-295X.84.4.353

Svinicki, M. D., \& McKeachie, W. J. (2014). McKeachie's teaching tips: Strategies, research, and theory for college and university teachers, Fourteenth Edition. Belmont, CA: Wadsworth,.

Teach, R. D., \& Govahi, G. (1988). The role of experiential learning and simulation in teaching management 
skills. Developments in Business Simulation and Experiential Learning, 15, 65-71.

Vos, L. (2014). Marketing simulation games: A review of issues in teaching and learning. The Marketing Review, 14(1), 67-96. http://dx.doi.org/10.1362/146934714X13948909473220

Vos, L., \& Brennan, R. (2010). Marketing simulation games: Student and lecturer perspectives. Marketing Intelligence and Planning, 28(7), 882-897. http://dx.doi.org/10.1108/02634501011086472

Vos, L., \& Brennan, R. (2012). Games improve marketing students' numeracy and financial skills? paper presented at the Academy of Marketing conference 2012.

Vosniadou, S., \& Ortony, A. (1989). Similarity and analogical reasoning. Cambridge University Press, Cambridge. http://dx.doi.org/10.1017/cbo9780511529863

Wellington, W. J., Faria, A. J., Hutchinson, D., \& Gowing, M. (2011). An interdisciplinary study of the impact of playing a marketing simulation game on student knowledge of management accounting/finance principles. Developments in Business Simulation and Experiential Learning, 38, 320-326.

Whiteley, T. R., Leduc, R., \& Dawson, B. (2004). A cognitive approach of the internal validity of a management strategy simulation game. Developments in Business Simulation and Experiential Learning, 31, 290-298.

Wolfe, J., \& Roberts, C. R. (1993). A further study of the external validity of business games: Five-year peer group indicators. Simulation \& Gaming, 24(1), 21-33. http://dx.doi.org/10.1177/1046878193241004

Young, M. R., Klemz, B. R., \& Murphy, J. W. (2003). Enhancing the learning outcomesL the effects of instructional technology, learning styles, instructional methods and student behaviour. Journal of Marketing Education, 25(2), 130-141. http://dx.doi.org/10.1177/0273475303254004

\section{Copyrights}

Copyright for this article is retained by the author(s), with first publication rights granted to the journal.

This is an open-access article distributed under the terms and conditions of the Creative Commons Attribution license (http://creativecommons.org/licenses/by/3.0/). 